\title{
Implementation Failures of an Information System: A Neuro Computing Approach
}

\author{
Bikram Pal Kaur* \\ Chandigarh Engineering College \\ Landran, Mohali, Punjab \\ India \\ ${ }^{*}$ Corresponding author
}

\author{
Himanshu Aggarwal, Phd. \\ Deptt.of Computer Engineering, \\ University College of Engineering, \\ Punjabi University, \\ Patiala 147002, India
}

\begin{abstract}
Information System (IS) is the current issue because the organizations are gaining competitive edge due to its successful implementation. Better performance of the organization depends upon the successful implementation of IS. The objective of this paper is to reveal the Neural Network (NN) method for determining the success and failure factors of Information System implementation on the basis of research conducted at two organisations of telecommunication industry. A quantitative survey based method was used to collect the data from the two organizations Reliance Communication Limited, Chandigarh and Punjab Communication Ltd. (Puncom) Mohali. The importance of the ensuing factors for implementation success/failure factors were identified from the opinion of the respondents of these organizations. Former organization is the global adopter of IS and is doing well in the market and the other one having in-house IS, not doing well in the current market. Seventeen variables were selected for the study relating to failure and success factors of Information System. This paper suggests that organizations must able to understand that IS is a Socio-Technical challenge and not only a technical or a managerial challenge. Therefore there is the requirement of modifying the existing processes or redesigning them in the second organization (Puncom, not doing well in the market) by comparing it with successful organization (Reliance) so that it may compete globally. The findings are discussed along with the implications of the research for the future work and also provide advice for both the academicians and practitioners that how to have the holistic improvement under IS.
\end{abstract}

\section{Keywords}

Information System Implementation, IS, Critical Failure Factors (CFFs), Critical Success Factors (CSFs), Telecommunication

\section{INTRODUCTION}

Information systems are the integrated systems having the mechanism based on implementation and forecasting which support the management in the decision making process and integrate different activities of the organisation. The benefits of IS is like right flow of information at all the levels of the management. The western countries and US give importance to the Information Systems.

There has been tremendous thrust on such studies in US and western countries but such zeal is missing in our country due to certain factors like environment, politics, social setup, culture etc. Each country has its own setup therefore such studies of US and west may not be applicable or useful in our country. The effectiveness of the IS is still very much required for every organization in India. But there is an absence of IS measures and IS success/ failure stories in our country.

It has been seen that most of the studies conducted have focused themselves on the success factors and neglect failure factors.

The study of the failures is equally important and yet not highlighted and therefore it is an important candidate of research.

The main purpose of this paper is to realize the method for determining the success/failure of the organization during implementation phase using Neural Network of SPSS 20. It identifies the potential IS success and failure factors along with their normalized importance

\section{LITERATURE REVIEW}

The review of IS literature suggests that for the past 15 years, the success and the failure of information systems have been major concern for the academics, practitioners, business consultants and research organizations.

A number of researchers and organizations throughout the world have been studying that why information systems do fail, [1] - [2].These studies highlight the following factors:

- Fear-based culture

- Political pressures.

- $\quad$ Poor training

- Technology focused

- Technical fix sought

- Poor reporting structure

- Poor consultation

- $\quad$ Project timetable slippage

- Complexity

- Inadequate testing

- Leading edge system,

- over commitment

- Development sites split

Six major dimensions of IS viz. superior quality (the measure of IT itself), information quality (the measure of information quality), information use (recipient consumption of IS output), user satisfaction (recipient response to use of IS output), individual impact (the impact of information on the behavior of the recipient) and organizational impact (the impact of information on organizational performance) had been proposed [3] All 
these dimensions directly or indirectly are connected to implementation of IS.

Cancellation of IS projects [4] are usually due to a combination of:

- Poorly stated project goals;

- Poor project team composition;

- Lack of project management and control;

- Little technical know-how;

- Poor technology base or infrastructure;

- Lack of senior management involvement.

- Escalating project cost and time of completion.

Further, some of the other elements of failure [5] emphasized in this study are:

- Approaches to the conception of systems;

- IS development issues (e.g. user involvement);

- Systems implementation;

- Organizational roles of IS professionals;

- Organizational politics;

- Organizational culture;

All the studies predict that during the past two decades, investment in Information Technology and Information System have increased significantly in the organization. But the rate of failure remains quite high. It is evident from the above said studies that the role of IT is only supportive rather it should be pervasive as emphasized by [7]. Therefore an attempt has been made to prepare the IS implementation model for the prediction of the success or failure of the organization as the goal of IS envisages pervasiveness.

Critical Success Factors (CSFs) for IS are the few key areas in which things must go right for an organization to thrive. If results in these areas are inadequate or deficient, the organization's efforts will be without reward. Further, these critical areas must be recognized and acted upon in an effective manner or it will not be possible to ensure success for a manager of an organization. Indeed, a logical conclusion and reasonable inference from this argument is that CSFs \& CFFs are the areas of activity that should be receive constant and careful attention from management.

Successfully adopting IT depends on user acceptance and actual usage of the system.

\section{OBJECTIVES AND SCOPE OF THE STUDY}

- $\quad$ To study the causes of failures and success of IS implementations.

- To develop a model of failure and success.

The objective of study was to analyze the failure and success factors of Information System and pinpoint the most important factors in implementation. Also, the study focuses on testing the relevance of the factors existing in literature in the Indian Telecom Industry. In view of the certain constraints like time and money, the study was confined to the two organizations, namely, Punjab Communication Limited (PUNCOM), and Reliance Communication, Chandigarh (Reliance). These enterprises were selected because they are using Information Systems. The former one is using the in-house IS and has low business performance and is late in adopting IS where as the later one early adopters of IT with functional IS using the international package of IS i.e. SAP(Systems Applications Products in Data Processing) for handing their business and the company has extremely good business performance and are high employment generators This industry is strategically and economically important due to high telecommunication need and is rapidly growing industry. It is also the backbone of the India because India is the second largest mobile user country of the world. The growth of this telecom industry is highest in the world as the mobile call is the cheapest in this country comparing to the whole world therefore it can play adequate role in expediting growth of the country.

\section{RESEARCH METHODOLOGY 4.1 Data collection tools}

Primary data has been collected through a questionnairecum-interview method from the selected respondents. The questionnaire was designed based on the literature survey, and detailed discussion with many academicians, professionals and industry experts. A total of seventeen variables were selected in this study relating to success and failure factors of Information System. A detailed analysis was performed by using Neural Network of SPSS 20 to identify Critical Success Factors (CSFs) and Critical Failure Factors (CFFs) between Puncom and Reliance. This study was also conducted on overall basis to have the holistic improvement under IS.

\subsection{Implementation of Information System}

The analysis had been made on the basis of the mean scores. The responses of the managers of the two companies differ significantly in terms of their mean scores. Among these companies, Reliance Communication Ltd. has been pioneer in implementation full-fledged Information System (IS) with fully automated procedures, processes and practices. The Puncom has a function-wise domestic IS, that is not well-integrated. IS is largely being used as a support tool by the Puncom managers.

\subsection{Scale reliability}

Reliability of the scale was studied for implementation using Alpha method of scale reliability. The Cronbach's Alpha was calculated for both Puncom\& Reliance.

The value of the Cronbach's Alpha was found to be greater than the standardized value of 0.6.This means the data is reliable. Hence both Puncom\& Reliance had attained value of $0.779 \& 0.891$ respectively and overall 0.956 . This establishes the reliability of the scale.

\section{Implementation Process for Information System}

The respondents had been divided into three levels i.e. top level, middle level and lower level. The various sub factors were evaluated under different factors as shown in table 1 
Table 1 Factors \& Sub factors for IS implementation

\begin{tabular}{|c|c|c|}
\hline $\begin{array}{l}\text { 1.Technological } \\
\text { Related Factors }\end{array}$ & $\mathrm{F} 1$ & $\begin{array}{l}\text { Up gradation of } \\
\text { Technology with time(up } \\
\text { gradation actual level) }\end{array}$ \\
\hline & F2 & $\begin{array}{l}\text { User support \& its } \\
\text { requirement specification(user } \\
\text { support actual) }\end{array}$ \\
\hline & F3 & $\begin{array}{l}\text { User Training in different } \\
\text { functional area(user training) }\end{array}$ \\
\hline & F4 & $\begin{array}{l}\text { Structuring (centralization) of } \\
\text { information systems(str.) }\end{array}$ \\
\hline & F5 & \begin{tabular}{|l} 
Integration of IS with other \\
organizational \\
units(IS
\end{tabular} \\
\hline & F6 & $\begin{array}{lr}\text { Technical } & \text { team } \\
\text { backend(Tech.actual) }\end{array}$ \\
\hline \begin{tabular}{|l} 
2, Web Based \\
Factors
\end{tabular} & F7 & $\begin{array}{lll}\text { Trade } & \text { rules } & \text { and } \\
\text { regulations(trade actual) }\end{array}$ \\
\hline \begin{tabular}{|l} 
3.IS service \\
perspective Factors
\end{tabular} & F8 & $\begin{array}{l}\text { IS handles business } \\
\text { functions (IS handlesactual) }\end{array}$ \\
\hline & F9 & $\begin{array}{l}\text { Operation of IS according to } \\
\text { business(operationISactual) }\end{array}$ \\
\hline & F10 & $\begin{array}{l}\text { Employees possess skills and } \\
\text { knowledge(Employ posses) }\end{array}$ \\
\hline & F11 & $\begin{array}{l}\text { IS manages all activities in } \\
\text { supply chain (IS manage).) }\end{array}$ \\
\hline & F12 & $\begin{array}{l}\begin{array}{l}\text { Flexibility, adaptability of IS } \\
\text { system }\end{array} \\
\text { to }\end{array}$ \\
\hline & F13 & $\begin{array}{l}\text { Documentation of operation, } \\
\text { usage, (documentation ) }\end{array}$ \\
\hline & F14 & $\begin{array}{l}\text { Maintenance, keeping up to } \\
\text { date IS(maintenance) }\end{array}$ \\
\hline $\begin{array}{l}\text { 4.Demographic } \\
\text { Factors }\end{array}$ & F15 & Gender \\
\hline & F16 & Seniority \\
\hline & F17 & Education \\
\hline
\end{tabular}

Seventeen variables were considered relevant for developing IS model on which the Neural Network is applied. The study of Neural Network is only to find the success \& failure factor of Reliance \&Puncom.

\subsection{Neural Networks}

It was explored from the literature that the above mentioned factors are contributing highly for IS implementation. The Neural network is applied in the IS application layer which considers responses on the Likert,s scale from all the three level of i.e. Top Management, Middle Management, Lower Management. The self learning capability of the neural network helps in making the decision regarding weights of the factors which are contributing for the developing of the model. For getting accurate results there was a need to minimize the prediction error for three selected level i.e. Top management, Middle management and lower management. Therefore Radial Basis Function (RBF) network was created. The network was the function of predictors (also called inputs or independent variables and target variable also called outputs) it was used to forecast the company how the improvements could be justified by exploring critical success \& critical failure areas. There are $\mathrm{p}$ samples $(\mathrm{x} 1, \mathrm{x} 2 \ldots \mathrm{xp})$, the corresponding factors \& covariates $(\mathrm{fl}, \mathrm{f} 2 \ldots \ldots \mathrm{fn})$, used to minimize the error between actual outputs (y1, y2----yn) by exploring hidden linkages to attain lesser error in the following results.

\subsubsection{Case study of Puncom organisation}

Taking the case of PUNCOM how model become failure model to identify failure factor among the pool of variables identified. As depicted by SPSS20 Neural Network using Radial Basis Function ( RBF ), network result were generated. This network first of all position the active data set of 159 samples of Puncom employees into training , testing \& holdouts in PUNCOM organization.

The result examined that $65.2 \%$ of samples was treated as training where $25 \%$ \& $9.8 \%$ came under testing \& hold out sample. Table 2 shows network information and displays all factor and covariates into input layers, 10 of hidden layer and output layer indicating the target variable i.e. Levels.

Table 2 Neural Network for IS implementation

\begin{tabular}{|c|c|c|c|}
\hline \multicolumn{4}{|c|}{ Network Information } \\
\hline \multirow{19}{*}{$\begin{array}{l}\text { Input } \\
\text { Layer }\end{array}$} & \multirow[t]{14}{*}{ Factors } & 1 & upgrationactuallevel \\
\hline & & 2 & usersupportactual \\
\hline & & 3 & usertraining \\
\hline & & 4 & str.actual \\
\hline & & 5 & IS Actual \\
\hline & & 6 & Tech. actual \\
\hline & & 7 & trade actual \\
\hline & & 8 & IShandlesactual \\
\hline & & 9 & operationISactual \\
\hline & & 10 & Employeepossesact \\
\hline & & 11 & ISmanageactual \\
\hline & & 12 & Flexibiltyactual \\
\hline & & 13 & documentaionactual \\
\hline & & 14 & maintenance \\
\hline & \multirow{3}{*}{$\begin{array}{l}\text { Covaria } \\
\text { tes }\end{array}$} & 1 & gender \\
\hline & & 2 & education \\
\hline & & 3 & seniority \\
\hline & \multicolumn{2}{|c|}{ Number of Units } & 56 \\
\hline & \multicolumn{2}{|c|}{$\begin{array}{l}\text { Rescaling Method } \\
\text { for Covariates }\end{array}$} & $\begin{array}{l}\text { Adjusted } \\
\text { normalized }\end{array}$ \\
\hline \multirow{2}{*}{$\begin{array}{l}\text { Hidden } \\
\text { Layer }\end{array}$} & \multicolumn{2}{|c|}{ Number of Units } & $10 \mathrm{a}$ \\
\hline & \multicolumn{2}{|c|}{ Activation Function } & Softmax \\
\hline \multirow{4}{*}{$\begin{array}{l}\text { Output } \\
\text { Layer }\end{array}$} & \multicolumn{2}{|l|}{ Dependent } & level \\
\hline & \multicolumn{2}{|c|}{ Number of Units } & 3 \\
\hline & \multicolumn{2}{|c|}{ Activation Function } & Identity \\
\hline & \multicolumn{2}{|c|}{ Error Function } & Sum of Squares \\
\hline
\end{tabular}

In table 3,the model summary showed the 10 hidden linkages that have reduced the error in testing sample . Hence RBF network tries to minimize error function during training \& testing sample. 
Table 3 Model for IS implementation

\begin{tabular}{|l|l|l|}
\hline \multicolumn{3}{|c|}{ Model Summary } \\
\hline \multirow{3}{*}{ Training } & Sum of Squares & 6.176 \\
\cline { 2 - 3 } & Percent Incorrect & $8.1 \%$ \\
\cline { 2 - 3 } & Training Time & $0: 00: 01$. \\
\hline \multirow{2}{*}{ Testing } & Sum of Squares & $2.771 \mathrm{a}$ \\
\cline { 2 - 4 } & $\begin{array}{l}\text { Percent Incorrect } \\
\text { Predictions }\end{array}$ & $9.1 \%$ \\
\hline \multirow{2}{*}{ Holdout } & $\begin{array}{l}\text { Percent Incorrect } \\
\text { Predictions }\end{array}$ & $15.4 \%$ \\
\hline Dependent Variable: level \\
\hline
\end{tabular}

To check the validity of these results the classification table 4 is used.

Table 4 Classification Table of samples for IS implementation

\begin{tabular}{|c|c|c|c|c|c|}
\hline \multicolumn{3}{|c|}{ Classification } \\
\hline Sample & Observed & \multicolumn{2}{|c|}{ Predicted } & \multicolumn{2}{l|}{} \\
\cline { 3 - 6 } & & 1 & 2 & 3 & $\begin{array}{l}\text { Percent } \\
\text { Correct }\end{array}$ \\
\hline Training & 1 & 4 & 1 & 1 & $66.7 \%$ \\
\cline { 2 - 6 } & 2 & 0 & 2 & 5 & $28.6 \%$ \\
\cline { 2 - 6 } & 3 & 0 & 0 & 73 & $100.0 \%$ \\
\cline { 2 - 6 } & $\begin{array}{c}\text { Overall } \\
\text { \%oage }\end{array}$ & $4.7 \%$ & $3.5 \%$ & $91.9 \%$ & $91.9 \%$ \\
\hline Testing & 1 & 2 & 0 & 0 & $100.0 \%$ \\
\cline { 2 - 6 } & 2 & 0 & 1 & 3 & $25.0 \%$ \\
\cline { 2 - 6 } & 3 & 0 & 0 & 27 & $100.0 \%$ \\
\cline { 2 - 6 } & $\begin{array}{c}\text { Overall } \\
\text { \%age }\end{array}$ & $6.1 \%$ & $3.0 \%$ & $90.9 \%$ & $90.9 \%$ \\
\hline \multirow{4}{*}{ Holdout } & 1 & 1 & 0 & 0 & $100.0 \%$ \\
\cline { 2 - 6 } & 2 & 0 & 0 & 2 & $0.0 \%$ \\
\cline { 2 - 6 } & 3 & 0 & 0 & 10 & $100.0 \%$ \\
\cline { 2 - 6 } & $\begin{array}{c}\text { Overall } \\
\text { \%age }\end{array}$ & $7.7 \%$ & $0.0 \%$ & $92.3 \%$ & $84.6 \%$ \\
\hline
\end{tabular}

The training sample $91.9 \%$ was compared with hold out sample $(84.6 \%)$. As the percentage was so near this means the model is correct and all the cases are correctly classified. Model excels in identifying top management, middle management than lower management.

This indicates that top \& Middle level both need to put their $100 \%$ to improve their company.

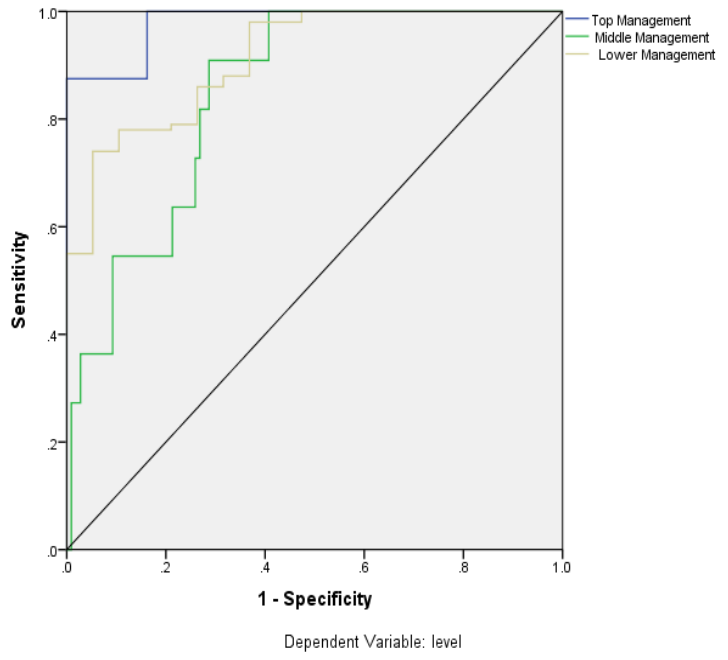

Fig 1 ROC Curve for Puncom

Fig 1 shows sensitivity by specificity by displaying Receiver operating characteristic (ROC) curve. ROC curves details the area and curve for each level.

For randomly selected respondent there probability or area was higher $(0.980)$ for the top management, then for the middle management $(0.848)$ and again higher for the lower management $(.913)$

The predicted pseudo probability of failure will be higher for employees linked with top Management .This means that in PUNCOM Organization Top management needs to substitute efforts in all project phase and there are lot of existing deficiencies amongst the top level which further disturbs the lower level.

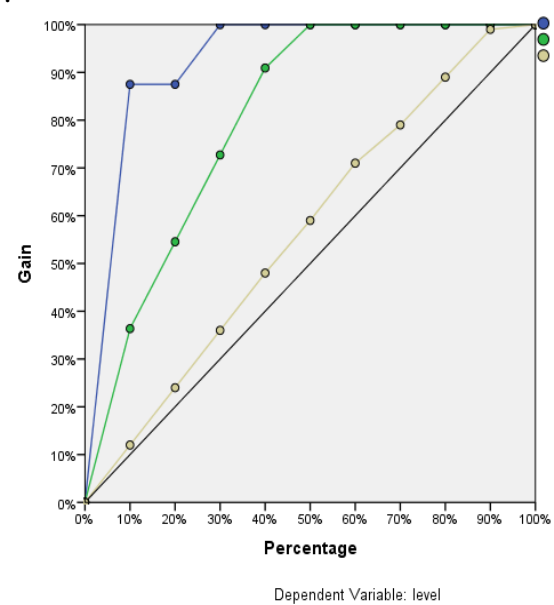

Top Management
Middle Management
Llo Middle Management
Lower Management

Fig: 2 Cumulative Gain Chart for Puncom

Fig 2 depicts the cumulative gain chart of organization called PUNCOM. Each and every specified point at different level can helps to catch the defaulters which indicates more and more failure rate. As it was observed the top level lies farther from the base line this means that company was deficit in decision makers among the top most level. Take the first point on Top level $(10,87 \%)$ means if we sort all the cases by predicted pseudo probability of Top level we would expert top $10 \%$ to contain $87 \%$ of all those cases that creates losses or failure of company under top level. Likewise $50 \%$ of work 
neglected by top management, deficit would increase to approximately $100 \%$. Least defaulters exists among the lower level than middle level .If there is proper direction in Planning by the top management in implementation, the company's IS system would definitely improve to a great extent. From the Fig.2. we conclude that the top management plays a pivotal role in leading PUNCOM towards failure followed by Middle and lower level management. Similarly in case of Middle management first $10 \%$ to contain $35 \%$ of cases that creates loss under Middle level, similarly it can be worked out for lower level.

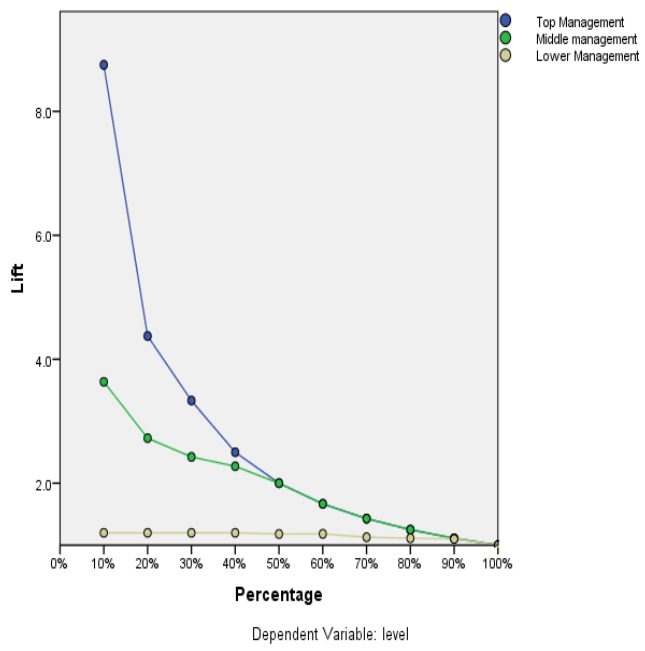

Fig: 3 Lift Chart for Puncom

Fig.3 depicts the lift chart which is delivered from cumulative gain chart. As we observed the lift of defaulters is highest among top level. If we increase the strength by $10 \%$ the lift of defaulters is $87 \% / 10 \%=$ $8.7 \%$. This means the organization can capture the defaults by 8.7 times , Further if we improve next $20 \%$, the lifts is $87 \% / 20 \%$ it would increase to 4.3 times more and so on, where the same can be studied in middle and lower level management . Maximum defaulters can be captured by neural networks. Now The question arise which variable should be given priority to use IS system effectively and lift the PUNCOM organization. Table 5 gives the normalized importance of each variable individually.

Table 5 Normalised Importance for different factors using NNmodel for Puncom (Ranking wise)

\begin{tabular}{|l|l|r|}
\hline $\begin{array}{l}\text { Independent Variable } \\
\text { Importance }\end{array}$ & $\begin{array}{l}\text { Normalized } \\
\text { Importance }\end{array}$ & Rank \\
\hline IS manage & $100.00 \%$ & 1 \\
\hline trade actual & $91.40 \%$ & 2 \\
\hline up gradation level & $86.20 \%$ & 3 \\
\hline user training & $84.60 \%$ & 4 \\
\hline IS Actual & $80.60 \%$ & 5 \\
\hline Maintenance & $75.80 \%$ & 6 \\
\hline Employee posses & $73.00 \%$ & 7 \\
\hline str. & $71.30 \%$ & 8 \\
\hline Tech. actual & $64.70 \%$ & 9 \\
\hline Flexibility & $64.70 \%$ & 10 \\
\hline IS handles & $58.60 \%$ & 11 \\
\hline
\end{tabular}

\begin{tabular}{|c|c|c|}
\hline Documentation & $49.10 \%$ & 12 \\
\hline operation IS & $45.80 \%$ & 13 \\
\hline Gender & $38.50 \%$ & 14 \\
\hline Education & $38.40 \%$ & 15 \\
\hline Seniority & $31.30 \%$ & 16 \\
\hline user support & $26.30 \%$ & 17 \\
\hline
\end{tabular}

Fig. 4 display the variables which are creating disturbances inside the company and are causes of serious concern. These variables are ISmanageactual (100\%), trade actual (91.4\%), upgrationactuallevel $(86.2 \%)$ etc.

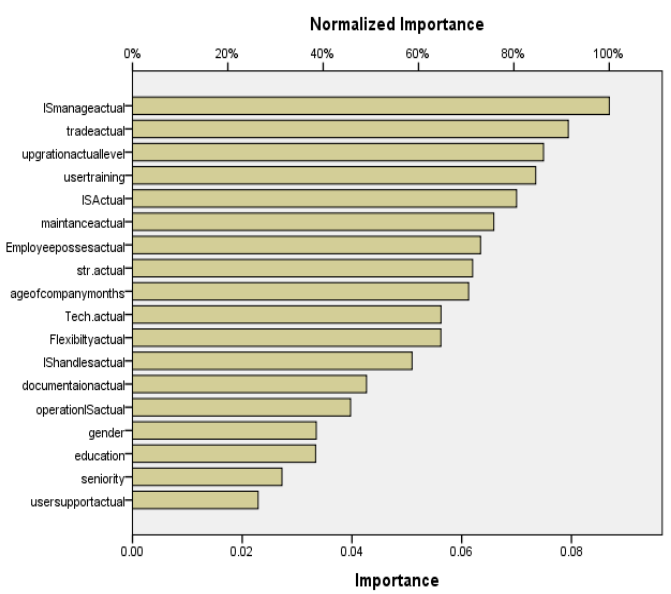

Fig: 4 Normalized Importances of Factors

Hence RFB not only minimize the error of responses but also extracts the variables with attached normalized importance, the variables can be named as critical failure factor for PUNCOM . Hence need to improve all variables identified by creating an effective top level management for implementing IS system in efficient manner.

\subsubsection{Case study of Reliance}

Taking the case of Reliance how IS model became successful for identifying success factors among the pool of variables. SPSS20 Neural Network, its Radial Basis Function had been used for getting the desired output .Using neural network results were generated. This network first of all positions the active dataset of samples into training, testing \& holdouts of Reliance Industry. The results show that $64.3 \%$ of sample is treated as training whereas $30.4 \%$ \& $5.4 \%$ comes under testing \& holdout sample.

Table 6 showed network information and displayed all the factors \& covariates into the input layer, 9 hidden layers and output layer indicating the target variable i.e. levels..

Table 6 Factors \& Sub factors for IS implementation

\begin{tabular}{|c|c|c|c|}
\hline \multicolumn{4}{|c|}{ Network Information } \\
\hline \multirow{5}{*}{$\begin{array}{l}\text { Input } \\
\text { Layer }\end{array}$} & \multirow[t]{5}{*}{ Factors } & 1 & upgration actual level \\
\hline & & 2 & usersupport actual \\
\hline & & 3 & usertraining \\
\hline & & 4 & str.actual \\
\hline & & 5 & IS Actual \\
\hline
\end{tabular}




\begin{tabular}{|c|c|c|c|}
\hline & & 6 & Tech. actual \\
\hline & & 7 & trade actual \\
\hline & & 8 & IShandlesactual \\
\hline & & 9 & operationISactual \\
\hline & & 10 & Employeepossesactual \\
\hline & & 11 & ISmanageactual \\
\hline & & 12 & maintanceactual \\
\hline & & 13 & documentaionactual \\
\hline & & 14 & Flexibiltyactual \\
\hline & Covariates & 1 & gender \\
\hline & & 2 & education \\
\hline & & 3 & seniority \\
\hline & Number of & & 50 \\
\hline & $\begin{array}{l}\text { Rescaling I } \\
\text { for Covaria }\end{array}$ & & Adjusted normalized \\
\hline Hidden & Number of & & $9 \mathrm{a}$ \\
\hline Layer & Activation & & Softmax \\
\hline $\begin{array}{l}\text { Output } \\
\text { Layer }\end{array}$ & $\begin{array}{l}\text { Dependent } \\
\text { Variables }\end{array}$ & 1 & level \\
\hline & Number of & & 3 \\
\hline & Activation & & Identity \\
\hline & Error Func & & Sum of Squares \\
\hline
\end{tabular}

The model summary displayed 9 hidden linkages that have reduced the error in testing sample to 4.7 from 7.8. Hence network tries to minimize error function during training \& testing sample as shown in table 7

Table 7 Model Summary for IS implementation in Reliance

\begin{tabular}{|l|l|l|}
\hline \multicolumn{2}{|c|}{ Model Summary } \\
\hline \multirow{2}{*}{ Training } & Sum of Squares Error & 7.866 \\
\cline { 2 - 3 } & Percent Incorrect Predictions & $33.3 \%$ \\
\hline Testing & Sum of Squares Error & $4.773 \mathrm{a}$ \\
\hline Holdout & Percent Incorrect Predictions & $33.3 \%$ \\
\hline
\end{tabular}

Table 8 Classification for IS implementation

\begin{tabular}{|c|c|c|c|c|c|}
\hline \multirow{3}{*}{ Sample } & \multirow{2}{*}{ Observed } & \multicolumn{4}{|c|}{ Predicted } \\
\cline { 3 - 6 } & & 1 & 2 & 3 & $\begin{array}{c}\text { Percent } \\
\text { Correct }\end{array}$ \\
\hline \multirow{4}{*}{ Training } & 1 & 2 & 0 & 2 & $50.0 \%$ \\
\cline { 2 - 6 } & 2 & 1 & 12 & 3 & $75.0 \%$ \\
\cline { 2 - 6 } & 3 & 0 & 6 & 10 & $62.5 \%$ \\
\cline { 2 - 6 } & $\begin{array}{c}\text { Overall } \\
\text { Percent }\end{array}$ & $8.3 \%$ & $50.0 \%$ & $41.7 \%$ & $66.7 \%$ \\
\hline \multirow{5}{*}{ Testing } & 1 & 3 & 1 & 0 & $75.0 \%$ \\
\cline { 2 - 6 } & 2 & 1 & 4 & 0 & $80.0 \%$ \\
\cline { 2 - 6 } & 3 & 1 & 3 & 4 & $50.0 \%$ \\
\cline { 2 - 6 } & $\begin{array}{c}\text { Overall } \\
\text { Percent }\end{array}$ & $29.4 \%$ & $47.1 \%$ & $23.5 \%$ & $64.7 \%$ \\
\hline & 1 & 0 & 1 & 0 & $0.0 \%$ \\
\cline { 2 - 6 } & 2 & 0 & 1 & 0 & $100.0 \%$ \\
\cline { 2 - 6 } & 3 & 0 & 0 & 1 & $100.0 \%$ \\
\cline { 2 - 6 } & $\begin{array}{l}\text { Overall } \\
\text { Percent }\end{array}$ & $0.0 \%$ & $66.7 \%$ & $33.3 \%$ & $66.7 \%$ \\
\hline
\end{tabular}

Table 8 shows the validity of the results, as the percentage of the training sample \& holdouts is $66.7 \%$ this means that the model was valid and correct. All the cases were correctly classified in the training sample, as NN model excels in identifying Top Management (50\%). Middle Management $(75 \%)$ and operational management. $(62.5 \%)$.This indicates that we need to be more cautions in identifying the potential respondent under middle management.

Fig.5 shows sensitivity by specificity by displaying Receiver operating characteristic (ROC) curve. ROC curve details the area under the curve for each level. For randomly selected respondents in Top level there is highest probability (.908) that the model depicted. The predicated pseudo probability of success will be higher for employees linked to Top management. This measures that Top level management is a good decision makers and introduces the work efficiently to middle \& lower level management.

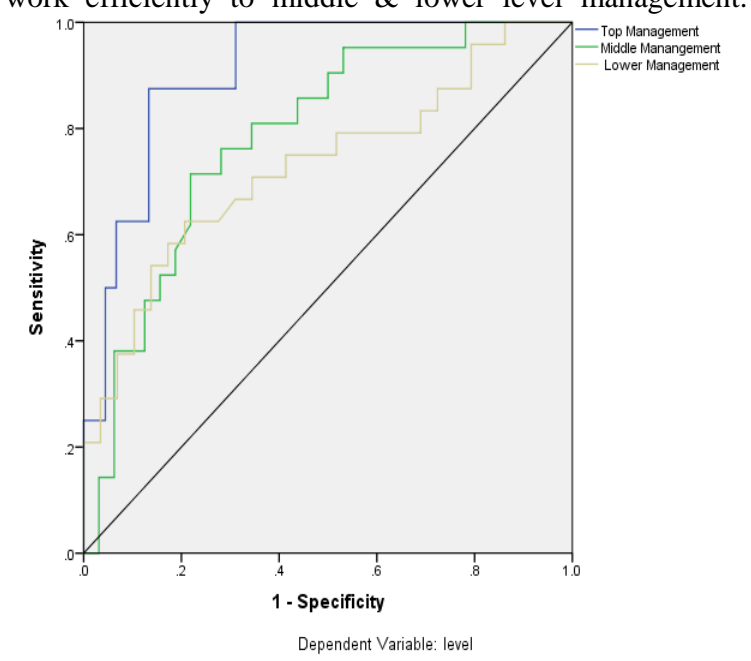

Fig: 5 ROC Curve for Reliance

Fig.6 depicts the cumulative gain chart of organization. Each and specified every point at different level can help to gain more and more success rate. As we see the Top level management lays farther the baseline more is the gain attained by the company. Take the first point on Top level $(10 \%, 50 \%)$ means if we sort all the cases by predicated pseudo probability of Top level we would expect top $10 \%$ to contains $50 \%$ of all the cases that actually creates gain under top level. Likewise $20 \%$ of work carried by top management, gain would increase to $60 \%$ and so on. If you select $100 \%$ of dataset you will obtain gain of $100 \%$. Similarly in other two categories. From this Fig.6 we conclude that top level management is helping the company to gain the most, followed by Middle and lower 


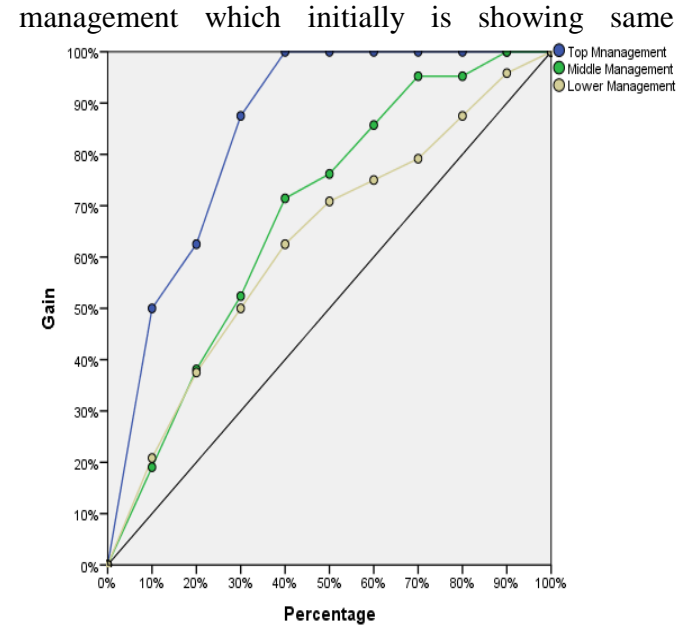

Dependent Variable: level

Fig: 6 Cumulative Gain Chart for Reliance

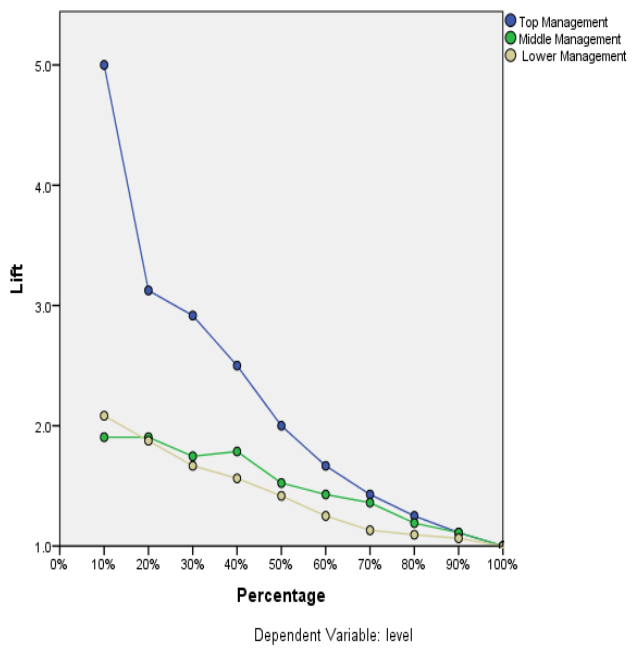

Fig: 7 Lift Chart for Reliance

Fig 7 depicts the lift chart which is derived from cumulative gain chart. As we observe the lift is highest among the top level. If we increase the strength by $10 \%$ of the top management, the lift is going to five times $(50 \% /$ $10 \%=5$ ). This means the organization can be lifted 5 times. Further if by improving $20 \%$ of the top management, the lift of the organization is $(60 \% / 20 \%=3) 3$ times and so on and so forth whereas same can be studied in middle and lower level managements. Now the question arises which variables should be given priority to gain and lift the Puncom organization. Table 09 gives the normalized importance of each variable individually. The Fig. 8 displays to attain success there is need to introduce and work on these variables like usertraining contribute for $100 \%$ success whereas as trade rules and regulation contribute $83.1 \%$ and so on

Table 9 Normalized Importance IS implementation

\begin{tabular}{|l|l|r|}
\hline Independent & Normalized & Rank \\
\hline & & 1 \\
\hline user training & $100.00 \%$ & 2 \\
\hline trade actual & $83.10 \%$ & 3 \\
\hline seniority & $71.80 \%$ & 4 \\
\hline IS manage & $69.90 \%$ & 5 \\
\hline Tech. actual & $67.70 \%$ & \\
\hline
\end{tabular}

\begin{tabular}{|l|l|r|} 
Flexibility & $67.70 \%$ & 6 \\
\hline education & $66.70 \%$ & 7 \\
\hline maintenance & $62.70 \%$ & 8 \\
\hline gender & $62.60 \%$ & 9 \\
\hline IS handles & $62.10 \%$ & 10 \\
\hline up gradation actual & $62.00 \%$ & 11 \\
\hline user support & $59.90 \%$ & 12 \\
\hline documentation & $58.50 \%$ & 13 \\
\hline Employee posses & $57.00 \%$ & 14 \\
\hline operation IS & $53.90 \%$ & 15 \\
\hline str. & $53.40 \%$ & 16 \\
\hline IS Actual & $38.90 \%$ & 17 \\
\hline
\end{tabular}

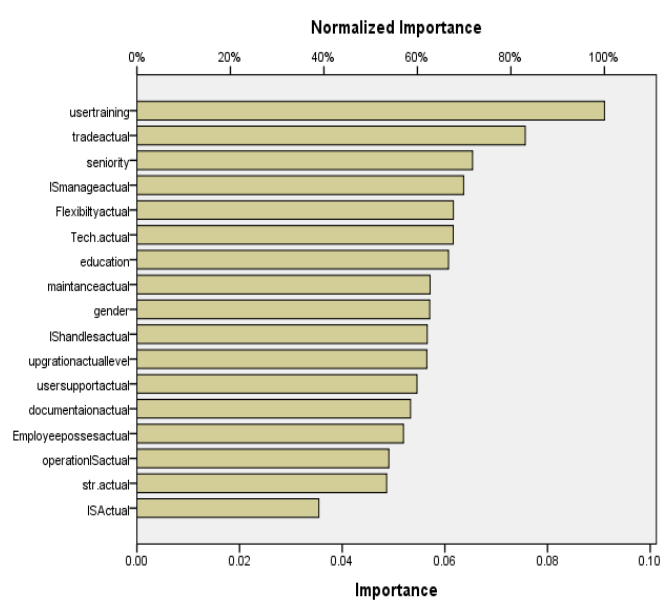

Fig: 8 Normalized importances of factors of Reliance

Hence a neutral network not only minimizes the errors of responses but also extracts the variables with attached normalized importance. This variable can be named as critical success factors for Reliance of utilizing systems in an efficient manner.

\section{RECOMMENDATIONS}

In the telecommunication industries IS play a vital role for the success or failure of the organization. It must be a part of the organization, so that the role of IS must be pervasive and not just a support.The role of the IS successful implementation in Reliance is highly due to the user training and involvement in IS. The organization follows web based trade structure and follows all the trade rules and regulation. Besides this the top management is highly involved in the successful implementation of IS. Since the Puncom industry has an in-house IS, it is mostly used as the transaction processing unit but not utilized as decision making unit. IS also does not manage all activities in supply chain, so this can be attributed a reason for the failure .In Puncom, organization also does not follow Web based trade structure, therefore ignoring trade rules and regulation .The other reason for persistent failure of IS implementation in Puncom is that there is no continuous up gradation of technology in time, they are using their inhouse IS which is sometimes not web compatible.

The implementation of IS in the communication industry is successful only if the top management is concerned about the new trade rule and regulations. Therefore there is a need of supportive management which led the team as a leader. Top management must provide user training for its 
successful implementation. User support \& its requirement specification are the pivotal sub factors for the successful implementation of the IS.

In Puncom the availability of Web based IS/IT resource based view (RBS) is found to be missing which the key factor for the success is of IS implementation globally. In house IS is nonflexible \& nonadaptable with the current market. Puncom organization is a public undertaking; certain trade rule \& regulation take so such time for the implementation then that of their competitors like Reliance.

Poor Documentation of operation, usage, support also leads to the failure of IS Implementation.

Maintenance, enhancement and keeping up to date of IS is the requirement of the successful implemented IS.

\section{CONCLUSIONS}

Our findings at the systems level will help the management in case the organizations make the implementation of IS effective at their organizational level. If the above concepts are implemented in their present ISs, the systems acceptance is very likely to improve because it would be based on how the effective implementation of IS is required for successful system. The study has many implications for both academic and practice communities. The results are especially important to the organisations seeking standardization of their ISs according to Indian culture and environment. Besides this, the study is important as it is empirical and pertains to large sector industry of three levels of the management having direct impact on the country's economy. Further, as there is a shortage of IS failure studies pertaining to the Indian industry and culture, the study can contribute significantly in evolving and conceptualizing an effective IS implementation model for IS in Indian Telecom industry.

Some of the important limitations of study were confinement to single industrial sector, fixed sized population evaluation, divergence from strict random sample selection, sticking to five point scales. The study has proposed CSFs and CFSs in IS implementation for Indian telecommunication industry. However; the study can be carried out for a large sample or organizations across the industries. Further, it will be extremely useful if the suggested factors are incorporated in the ISs of the considered organizations.

\section{REFERENCES}

[1] Angeliki Poulymenakou1 and Vasilis Serafeimidis2, Volume1, number 3, 1997, "Failure \& Lessons Learned in Information Technology Management", Vol. 1, pp. 167-177.

[2] DeLone, W.H., and McLean, E.R. 2004. "Measuring E-Commerce Success: Applying the DeLone\& McLean Information Systems Success Model," International Journal of Electronic Commerce (9:1), fall, pp 31-47.

[3] Flowers, S. (1997), "Information systems failure: identifying the critical failure factors," Failure and Lessons Learned in Information Technology Management: An International Journal,Cognizant Communication Corp., Elmsford, New York, NY, Vol. 1 No. 1, pp. 19-30.

[4] J Jay Liebowitz , "A look at why information systems fail Department of Information Systems," Kybernetes, Vol. 28 No. 1, 1999,pp. 61-67, () MCB University Press,0368-492X, University of MarylandBaltimoreCounty, Rockville, Maryland, USA.

[5] KwekuEwusiMensah, "Critical issues in the abandoned information system development projects", LoyolaMarymountUniversity, Los Angeles, CA, Volume 40, Issue 9(September 1997) pages $74-$ 80, 1997, ISSN: 0001-7082.

[6] Xiang-Hua Lu a, ${ }^{*}$, Li-Hua Huang a, Michael S.H. Heng b Adelaide, SA, Australia,"Critical success factors of inter-organizational information systemsA case study of Cisco and Xiao Tong in China" Available online 6 October 2005 ,Information \& Management 43 (2006) 395-408

[7] Aggarwal, H., Goyal, D.P. and Bansal, P.K. (2005) 'A change model based on an integrated approach for strategic business information technology alignment for sustainable competitive advantage', Paradigm, Vol. 9, pp.128-138. 